\title{
Red cell aggregation in dextrose solutions
}

\author{
J. H. JONES ${ }^{1}$, G. S. KILPATRICK, AND E. H. FRANKS ${ }^{2}$ \\ From the Welsh National School of Medicine, Cardiff
}

SYNOPSIS Red blood cells aggregated by $5 \%$ dextrose solutions are rapidly destroyed in the circulation, as demonstrated by radio-chromium studies. Possible mechanisms are discussed.

The aggregation of red blood cells into macroscopic clumps in the presence of $5 \%$ dextrose solutions is a familiar sight to most clinicians who have transfused blood and dextrose in succession through the same giving-set, particularly since the introduction of transparent plastic tubing (Fig. 1). As the proportion of dextrose to blood increases within the tubing, the residual red cells form large aggregates which are capable of obstructing the lumen of the needle. The phenomenon is reversible since the addition of small amounts of electrolytes causes the clumps to disperse: this is presumably what occurs should these aggregates enter the circulation.

In an attempt to determine whether this aggregation has any clinical significance and if possible to elucidate its mechanism, red cell survival studies were made using radio-chromium.

\section{MATERIALS AND METHODS}

DeXtrose The $5 \%$ dextrose solutions used in this investigation were prepared according to B.P. specifications for infusion.

RADIO-CHROMIUM TAGGING Samples of blood, each of $10 \mathrm{ml}$., were taken from normal subjects and the cells labelled with approximately $75 \mu \mathrm{g}$. ${ }^{51} \mathrm{Cr}$. as sodium chromate by a modification of the established method (Wetherley-Mein, Epstein, Foster, and Grimes, 1958). The suspension was then centrifuged, the supernatant fluid replaced by $20 \mathrm{ml} .5 \%$ dextrose solution and after 15 minutes the fresh suspension was re-injected into the donor's circulation. Erythrocyte survival was studied by examination of samples taken 15 minutes and one hour after the injection and subsequently at daily intervals for four days. Assessment of red cell destruction was expressed as 'percentage chromium loss per day', up to $5 \%$ chromium loss per day being accepted as normal.

\section{Received for publication 20 July 1961.}

'Present address: Department of Pathology, Royal General Hospital, Newport, Mon.

${ }^{2}$ Department of Anaesthetics, Royal Infirmary, Dundee.

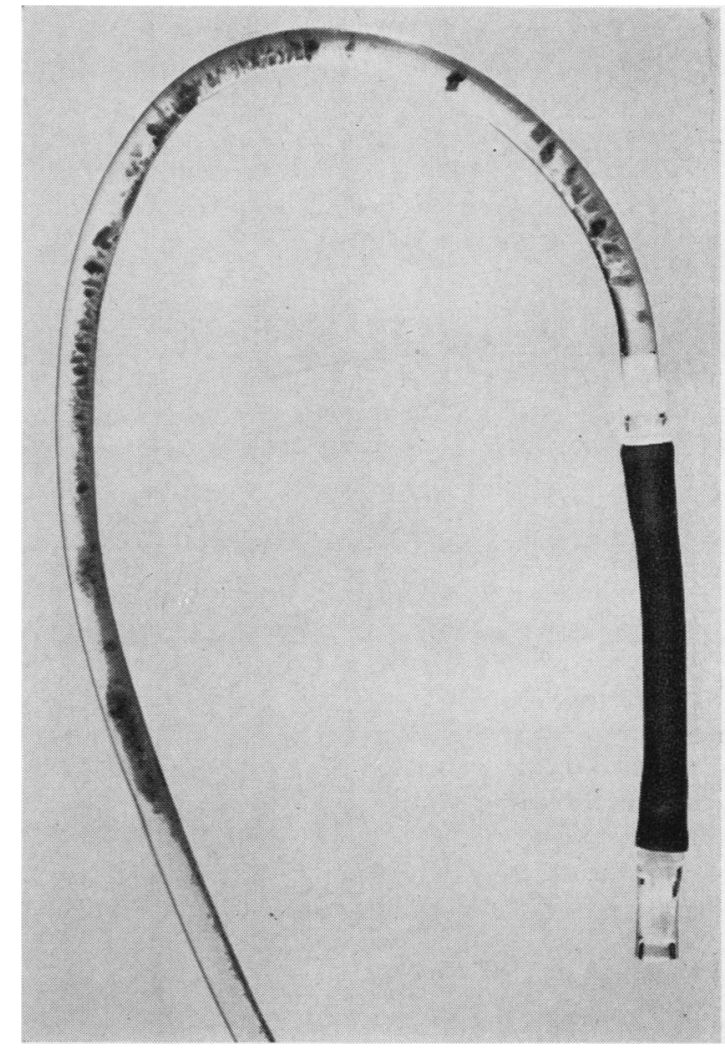

FIG. 1. The formation of red cell aggregates in $5 \%$ dextrose solution within transfusion tubing.

RESULTS

The survival of dextrose-aggregated cells was studied in three individuals. There was no destruction apparent within one hour of injection but in the subsequent 48 hours radioactivity fell to 21,26 , and $29 \%$ showing a rapid destruction of the injected cells. 


\section{DISCUSSION}

The phenomenon of red cell clumping in isotonic dextrose solutions has been known for a considerable time. It is generally accepted that the cause is an absence of electrolytes in the suspending medium as all solutions of non-ionizing substances will induce an aggregation of the cells which can be dispersed by the addition of sodium chloride to a concentration of $0.09 \mathrm{M}$.

Studies of the phenomenon have shown that, apart from aggregation, the red cells undergo considerable biochemical changes: the normal selective permeability of the cell membrane is disturbed so that both anions $\mathrm{Cl}$ and $\mathrm{HCO}_{3}$ (Jacobs and Parpart, 1933) and cations such as K (Maizels, 1935) leave the cell. Furthermore, Ponder (1926) has shown that dextrose solutions appear to inhibit the action of the haemolysins, saponin and taurocholate, and concluded that the effect of the dextrose was on the cell itself rather than on the lysin as it was not reversed by washing the cells after their exposure to dextrose.

It has been generally accepted that aggregation is caused by the anion shift across the cell membrane, resulting in a difference in $p \mathrm{H}$, the cells becoming alkaline and the medium more acid. Davson (1939), however, was of the opinion that, so far as the cation permeability was concerned, this could not be explained on these grounds and suggested that an actual structural change in the cell membrane occurred.

Our observations suggest that although the agglutination is reversible, the cells have lost their capacity to survive and are rapidly removed from the circulation. Whether this is due to structural change in the cell membrane or to a loss of phosphoric esters from the cells, as Maizels (personal communication) suggests, is not clear but at all events the change appears to be irreversible.

Because of the small numbers of cells affected by the mixing of blood and dextrose solutions during a transfusion, it would seem unlikely that any harmful effects would occur from the destroyed cells in an adult although this may not be true in infants.

We would like to suggest, however, that the high incidence of post-transfusional thrombophlebitis after dextrose (Handfield-Jones and Lewis, 1952 McNair and Dudley, 1959), previously ascribed to alternations in $p \mathrm{H}$ or changes in chemical composio tion of the fluid as a result of autoclaving, might be the direct result of the changes undergone by the redp. cells in the presence of dextrose. This is in keepin with the findings of Bolton Carter, Milne, and Whittet (1952) that the addition of buffers or colde sterilization (McNair and Dudley, 1959) did noP reduce the incidence of thrombophlebitis after $\overrightarrow{\mathrm{c}}$ dextrose.

It seems likely that thrombophlebitis could b precipitated by these red cell changes either through. the entry of small aggregates into the vein forming or nidus for the development of subsequent thrombosis. or it could possibly be brought about through the presence of thromboplastic material known to be liberated from haemolysed red cells. Although our results seem to suggest that there is no immediate destruction of the cells, it is possible that thrombo plastic lipids are released from cells which have undergone gross structural changes as shown byo their subsequent failure to remain in the circulations

The increased incidence of thrombophlebitis, the mechanical difficulties of blocked needles with reo cell aggregates, and the possibility of shortened rec cell survival suggest that dextrose saline solution (containing $4.3 \%$ dextrose with $0.18 \%$ saline) shouldo be used instead of dextrose in all patients except the few in whom strict limitation of sodium is required윽

We would like to thank Mr. R. G. Wood for help with the isotope studies, Mr. R. J. Marshall for the photos graph, and Mr. D. Elkington for technical assistance.

\section{REFERENCES}

Carter, J. F. Bolton, Milne, Elizabeth M., and Whittet, T. D. (1952)? Lancet, 2, 660.

Davson, H. (1939). Biochem. J., 33, 389.

Handfield-Jones, R. P. C., and Lewis, H. B. M. (1952). Lancet, 1, 585

Jacobs, M. H., and Parpart, A. K. (1933). Biol. Bull. Wood's Hole $65,512$.

Maizels, M. (1935). Biochem. J., 29, 1970

McNair, T. J., and Dudley, H. A. F. (1959). Lancet, 2, 365.

Ponder, E. (1926). Proc, roy. Soc. Lond. B., 99, 461.

Wetherley-Mein, G., Epstein, I. S., Foster, W. D., and Grimes, A. J (1958). Brit. J. Haemat., 4, 281. 